\title{
1. Introduction: Janus meets Proteus in the platform economy
}

\author{
Jan Drahokoupil and Kurt Vandaele
}

\subsection{THE ORGANIZATION OF WORK IN THE PLATFORM ECONOMY}

Platform companies are market makers. They unleash market forces from the constraints of hierarchies and long-term contracts. Digital technology and the internet have allowed platform companies to run digital marketplaces that can link clients across the globe, with cost structures that allow mediation of the cheapest services through sophisticated matching mechanisms. A search on the internet triggers an auction in which one's attention is sold to the advertisers before the results are displayed. That spare room might not need to stay idle for the night. Platforms also make matching less arduous. A dating app saves one an awkward visit to a dodgy bar, or the need to sign up for a dance class.

The world of work has not been immune to restructuring by platforms. Digital labour platforms organize marketplaces that match supply and demand for paid work. Long-term engagements are thus replaced by one-off transactions. Jobs are transformed into tradeable tasks. Employment agencies have long been in the business of matching workers with their clients, but only labour platforms promise to get away from the hierarchies and long-term contracts that tie workers in the employment relationship. Digital labour platforms thereby transform labour markets from markets for jobs to markets for tasks. Although the platform workforce is apparently relatively small in terms of employment, the economic transformation symbolized by labour platforms has attracted considerable attention, triggering imaginations about the new flexible future for the world of work. While some have welcomed, if not celebrated, the emancipation, freedom and autonomy this gives to workers, others have fretted about the loss of social protection for the most vulnerable workers and the prospect of algorithmic enslavement and race-to-the-bottom terms and conditions of work.

Combining Janus and Proteus - figures from Roman and Greek mythology, respectively - might be an appropriate fit to describe the current and complex 
state of digital labour platforms. First, regarding the temporal dimension, labour platforms have a Janus face: they are combining the 'new' with the 'old'. The 'new', or discontinuity, refers to the platforms' use of digital technology, the algorithmic management approach and the 'production and commodification of data' (Grabher and Köning 2020, p. 106), but it relates as well, perhaps more importantly, to their narrative ability to produce a discourse of novelty and disruptiveness which, at the same time, 'function[s] to detract attention from underlying continuities and constitutive contexts' (Peck and Philipps 2020, p. 82). The 'old' concerns the types of employment practices and intermediation that are reminiscent of informal and triangular work arrangements during earlier phases within capitalist development in the Global North, although this still exists in certain industries today. Thus, in practice, the borderline between platform work and non-standard and casual employment is blurred so that the employment status of platform workers is often contested. Second, concerning the spatial dimension, just like the prophetic sea god Proteus, labour platforms can take numerous forms and shapes influencing workers' experiences and potentially their resistance to, for instance, algorithmic control. One could distinguish between the scale of tasks mediated, ranging from micro to large-scale project work, the nature of the skills involved and the system of task distribution such as the direct allocation of offers, auctions or contests (see also Florisson and Mandl 2018). Moreover, as so often, context matters: institutions and policies shape the prevalence of platform work and the conditions within it.

One of the key distinctions in the Proteus-like heterogeneity of platform work relates to the format of service provision and to that of the geography of the respective market. Location-based platforms offer services that are delivered and performed in or around the locality while the intermediation occurs online. They include ride-sharing, food delivery and domestic services like care work, cleaning and repair and maintenance. Matching supply and demand in local markets for physically delivered services, location-based platforms are often run by international operators that might be considered transnational corporations. The limited scalability of their markets leaves space also for companies operating locally, however. A different case is what we call online platforms. The latter, including, for example, Amazon Mechanical Turk, TaskRabbit or Upwork, organize digitally delivered services that can, in principle, be delivered from anywhere in the world. Online platforms thus have the potential to operate on a global scale. Yet, in practice, they are characterized by regional divisions and distinct geographies of operation. The distinction between location-based and online platforms, and hence between location-based and online platform work, is related to the main differences in opportunities for worker organizing and alliance-building, regulatory issues and challenges and that of business strategies. According to the International 
Labour Organization (ILO), the number of location-based platforms increased almost ten-fold in the period between 2010 and 2020 while the number of online platforms tripled (ILO 2021).

This key distinction between location-based and online labour platforms informs many of the comparative chapters in this book and it structures our organization of the material. The book aims to provide a guide to the diverse landscape of platform work. It delivers a comprehensive overview of the key issues relating to labour in the platform economy, focusing in particular on the challenges for labour agency, including the role of institutions and policies. Designed to provide a stimulating guide to the current research landscape, it offers comparative overviews of the key topics followed by case studies of platform work from across the globe. The case studies cover working conditions in major segments of platform work and focus on the strategies, struggles and resistance of the workers involved. Covering the diversity of platform work in a global comparative perspective, the experience of different world regions is intersected with the variety of the platform economy.

Part I of the book puts digital labour platforms in their historical, economic and geographical context. It also considers the implications of platform work for working conditions and worker health and tackles the challenges of measuring the extent and nature of platform work. The rise of labour platforms is thus situated in the context of the range of forces that are driving change in the organization of work and that act towards undermining the 'standard employment relationship' (Bosch 2004). The employment relationship has played a key role in regulating labour relations and organizing protection for workers, including social insurance. Such a relationship has been less prominent in developing countries, however, where large parts of the workforce earn their living in the informal economy without any access to social insurance and other forms of social protection. The emergence of platform work thus has different implications in such contexts, possibly offering a way of formalizing the labour market.

Labour platforms are therefore part and parcel of longer-term processes of work externalization and value chain fragmentation. Driven by the search for allocation efficiency, cost savings and regulatory arbitrage, these processes can be observed, in different forms and with different implications, across the world. Digital technology is a key enabler of this process but the outcomes are not determined by it. Policies and institutions not only shape the outcomes but also enable the rise of the platform economy and platform work. Drawing on comparative evidence, the chapters in Part I also help to understand the diversity of labour platforms and the types of work mediated through them.

Part II addresses the regulatory response to platform work and the role of institutions in shaping the outcomes. The chapters are motivated by the question of what regulatory framework is needed to support good working 
conditions for platform workers and guarantee their fundamental rights, taking into account self-regulation by the platforms, regulation via collective bargaining and legal regulation. It considers in particular the role of the conventions of the ILO and regulation at European level. Above all, the question of the employment status of platform workers dominates discussion of the regulatory responses. The combination of the high degree of worker control by the platform and working time arrangements that allow flexibility and short-term engagements has made some forms of platform work sit uneasily within many regulatory frameworks. Another source of legal uncertainty is the question whether platform workers, working on a self-employed basis, can conclude collective agreements without breaching competition law. The list of regulatory issues is much longer, however. For instance, there is the issue of the fees charged by some platforms to workers; there is the lack of redress in the event of refusal of payment for completed work or the suspension or closure of worker accounts; the automated systems for rating and allocating work are often opaque and error-prone; and clients or platform operators, or both, often do not communicate with workers to resolve issues (Silberman and Johnston 2020).

In the case of location-based platform work, the key regulatory challenge is to make the existing regulations fit for purpose. Online platforms are more difficult to regulate as a larger number of jurisdictions are typically involved and organizing workers collectively is challenging, where even possible. ILO conventions may represent a way of addressing some of these issues (see ILO 2021). In practice, however, the international labour movement may need to rely on voluntary codes of conduct, alliance-building with non-governmental consumer organizations and informal worker coordination in digital online communities, although the forums and other types of online interaction are often not independent of the platforms themselves (see, for example, Bucher et al. 2020; Gegenhuber et al. 2020; Gerber 2020; Gerber and Krzywdzinski 2019; Panteli et al. 2020; Wood and Lehdonvirta 2019; Wood et al. 2018).

The remainder of the book investigates how these general trends play out in the individual types of platform work across the globe. Part III encompasses three case studies of online labour platforms while Part IV consists of six case studies of location-based platforms either in private or public settings. The studies indeed underline the diversity of experience of platform work. For some platform workers, particularly those working on online platforms in lower-income countries, it provides good pay, often higher than alternatives in the offline economy. At the same time, remuneration on online platforms tends to be characterized by large inequalities between platform workers in a single place. Even poorly paid online work, such as microwork, can be attractive for other reasons, however. These include the lack of a commute or the possibility of combining it with other work or care obligations. Relatively low remuner- 
ation tends to characterize location-based labour platforms that are able to tap into a pool of low-skilled workers, often migrants, who tend to be abundant on the labour market or who are willing to take a poorly paid job for limited access to the regular labour market. In such a context, adequate pay can be achieved by guaranteeing platform workers a minimum wage or coverage by a collective agreement.

The case studies also identify the problems associated with platform work in terms of insecurity, poor work-life balance and discrimination. Online platform workers, in particular, suffer also from social isolation. A general problem experienced by both location-based and online platform workers is a lack of skills development and training opportunities in platform work and hence their low employability outside of this low-skilled work. Despite its potential to formalize activities that would otherwise happen in the informal economy, much of platform work is, in fact, not declared and workers are not covered by social protection. This also creates a fiscal problem for the states that, among others, finance the education of these workers but do not recuperate this investment through taxation. Finally, location-based platform work often entails dangerous health and safety practices. This is most evident in the case of food delivery in which algorithmic management often puts workers under considerable pressure for speedy delivery.

Working time flexibility and - more generally - the ability to work autonomously as 'your own boss' is often seen as a key benefit of platform work. It is also the reason why workers take up, and value, platform work (Adams-Prassl and Berg 2017; Lehdonvirta 2018; Pesole et al. 2018). Platform work is, however, characterized by diverse experiences in this respect, too. Many platform workers benefit from flexible work arrangements and, for some, it is the reason why they are willing to accept lower remuneration. At the same time, our case studies contribute to the body of evidence that shows that, for many platform workers, working time flexibility is only notional (Drahokoupil and Piasna 2019; Schor et al. 2020; Piasna and Drahokoupil 2021). The nature of work, or the need to maximize work to earn sufficient income, often limits the scope for exercising control over working time. Many workers need to work long hours to earn sufficient income, putting in hours that substantially exceed the standard in regular employment. Platform workers often spend a lot of unpaid time waiting and searching for adequate work while facing costs related to fluctuations in demand and the loss of income when demand is low (Berg 2016; Kuhn and Maleki 2017; Wood et al. 2019). Our evidence from food delivery also shows incentive structures that encourage long hours. Moreover, algorithmic management often actually imposes authority structures that leave workers with little autonomy (Aloisi 2020). Again, as shown in the case studies, food delivery is a case in point: workers experience their 
work as a complete subordination to the algorithms of the company's platform (see also Cant 2018).

Finally, the evidence presented in the case studies also contributes to the debate on worker preferences vis-à-vis working time flexibility and security triggered by the rise of platform work. The debate is often centred around the alleged trade-off between the schedule flexibility of self-employment on the one hand and the protection offered by employment status on the other (Hall and Krueger 2018; Berger et al. 2019). In fact, worker protection and flexible work arrangements can both be understood as the means towards a single end: enhancing worker autonomy and control over the conditions of work. Interested in exercising autonomy and control, workers might, in fact, have ambiguous preferences towards employment status. They are informed, among others, by the specific trade-offs in a given regulatory framework and shaped by the uncertainty about alternative arrangements (Dubal 2020). Income security, in particular, is often valued by workers but guaranteeing a minimum income (especially a minimum hourly wage) may require a more regulated schedule that restricts extreme forms of working time flexibility. The devil is in the detail. Employee status may entail considerable schedule flexibility (see also Berg et al. 2004). Self-employment, in turn, may provide a degree of autonomy and control if incomes are predictable and workers can influence their conditions of work (for example, Dubal 2017).

\subsection{KEY ISSUES OF PLATFORM WORK AND ITS CONTEXT: CHAPTERS 2 TO 7}

Platforms make and organize markets: they enable their customers to interact with each other, coordinate demand on both sides of the market they serve and lower the transaction costs involved. Market making by platforms has particularly significant implications in the world of work in which it shifts the provision of labour from employment relations, characterized by longer-term engagements and worker protection, to one-off transactions on open markets.

The economic role of platforms is discussed by Jan Drahokoupil in Chapter 2. It distinguishes between the intermediary role of labour platforms, which has specific implications as far as the market for labour is concerned, and the infrastructure role. The latter allows the platforms to structure interactions between clients through its regulatory power and, less directly, by behavioural design. These roles are associated with three distinct business models: regulatory arbitrage; an intermediation business relying on network effects; and a surveillance business associated with infrastructural power.

In practice, labour platforms pursue regulatory arbitrage and the intermediation model. Turning either of them into a successful business strategy is fraught with difficulties, however. 
Regulatory arbitrage exploits the cost advantage of replacing employment relations with one-off market transactions via the use of 'independent contractors'. As many aspects of managerial prerogative are built into algorithmic management and performance and monitoring systems, working with independent contractors is a highly ambiguous arrangement, albeit one that is (legally) contested and thus uncertain. It also means facing collective organizing efforts and worker resistance. At the same time there are cases, particularly in Nordic Europe (see Jesnes and Nordli Oppegaard 2020), where the operation of labour platforms goes hand in hand with a genuine employment relationship, although the arrangements are somewhat unusual featuring contracts of a rather non-standard nature. Even outside Nordic Europe, it should be added that some labour platforms have not made use of 'independent contractor' status in the first instance but only returned to it later on.

Furthermore, a notable case has also been the arrangement set up by the labour market intermediary and member-owned and governed cooperative SMart (Société mutuelle pour artistes) for platform-based food delivery couriers in Belgium (Charles et al. 2020; Drahokoupil and Piasna 2019). This wage portage arrangement put the couriers in a genuine employment relationship, providing them with an extra guarantee that legal minimum employment rights would be respected by the platform. Trade unions considered the arrangement as the second-best option in anticipation of the regulatory employment classification of the couriers (Vandaele 2020; see also Xhauflair et al. 2018). The SMart arrangement ended in early 2018, though, when Deliveroo unilaterally decided to work only with ad hoc contracts largely devoid of minimum standards or social protection.

The intermediation model of labour platforms allows the generation of income from matching without the need to invest in underlying assets. Network effects promise monopoly rents. Market dominance is not guaranteed, however, and the costs of sustaining the network effects can be considerable. It is the latter in particular that puts question marks over location-based platforms as an unstoppable juggernaut. They have to create and sustain network effects in price-sensitive, fragmented markets, in each and every location, while upscaling network effects is not possible as, by definition, location-based platforms are restricted to the location. In general, while labour platforms save costs on capital equipment and its maintenance, they also need a critical mass of users and clients or customers in order to gain liquidity and become self-sustaining, while both users and clients have the possibility of using multiple platforms so that loyalty to the platform is undermined. Sustaining the network effects therefore implies the need for continued investment. Also, there might be possibilities for users and clients or customers simply to circumvent the platform as an intermediary. 
Given all these difficulties, is it any wonder that the profits of labour platforms, at least the publicly listed ones, and location-based platforms in particular, are close to non-existent so far? Still, the prospect of monopoly rents can seduce investors while the ability of some platforms to capture and utilize data about transactions, users and customers seems also of importance in investment decisions.

The platforms' control of workers' economic assets obtained from user-generated data - their ratings and their status they themselves have earned - is a key question for the engagement of regulatory institutions since it concerns, ultimately, the ownership of data. Within the workplace there are important debates concerning the use of surveillance software, not least with the rise of remote working for office workers under Covid-19, and the data which platform workers generate while going about their work fit precisely into that set of debates. At national level, it is clear that the commissions and agencies responsible for information privacy need to be both better engaged in those debates and more understanding of and responsive to the types of issues being raised - and the same is true of regulatory agencies at international level where there is a degree of policy coordination. It seems that such agencies have been somewhat behind the curve when it comes to the workplace; and that platforms have latched onto this rather unfortunate lack of market intelligence.

Much of the discussion and research focuses on consumer-facing platforms and less is known about business-to-business platforms (see also Grabher and van Tuij1 2020). The extent to which companies in the conventional economy are utilizing digital labour platforms, and the forms this takes, is addressed by Pamela Meil and Mehtap Akgüç. In Chapter 3, they explore the linkage between digital labour platforms and conventional labour markets, situating the platform model in the context of global production networks and long-term value-chain restructuring.

Data collection on the specific types of activities performed on labour platforms is difficult: either this belongs to the internal operation of companies, while the list of business clients on the websites of some labour platforms can simply be considered as marketing, or it might hide complex processes of outsourcing within the value chain. Nevertheless, based on the distribution of work, the authors discern three outsourcing patterns of interaction between labour platforms and companies across a diverse set of industries in the conventional economy. Two of these patterns are in accordance with the two types of the online platform economy: jobs and tasks that can be considered microwork, also known as 'ghost work' (Gray and Suri 2019), which can be reintegrated into the company without much effort; and (stand-alone) macrowork being similar to freelance work and which needs little reintegration as the tasks are mainly separated from (day-to-day) company processes. The third pattern relates to platforms as an intermediary coordinator and manager of dispersed 
activities, making their status as labour platforms, rather than service suppliers, contested. Such companies split complex tasks, organize their sourcing and execution, and then integrate them as a solution for the client.

While those three patterns are dominant, this does not exclude, however, that companies could make use of location-based platforms, like cleaning services, although this use of (personal) services by companies seems of secondary importance. Future in-depth case studies are needed here for further deepening and juxtaposing of the different patterns. Even so, outsourcing via labour platforms is a continuation of the long-term trend of the externalizing of activities within companies across expanding value chains. This process affects the working conditions and pay of workers in client companies who find themselves negotiating with their employer in the shadow of the conditions of the externalized workforce (for example, Drahokoupil 2015).

While it can be assumed that the connection between labour platforms and companies is intensifying, its amplitude is uncertain. Simultaneously, the relationship between labour platforms and the conventional economy has a certain Faustian overtone, at least in the Global North. Platforms are 'free-riding' on the conventional economy and taking their gains, ignoring the consequences for the latter (see also Schor et al. 2020). This clearly holds true if it concerns platform workers for whom the income retrieved from platform work is supplementary either because they have another (main) job or they are entitled to social benefits. Put differently, labour platforms are hinging upon existing labour markets in the conventional economy and social protection systems, whereas their 'creative destruction' tends to undermine existing labour market regulations and tax-financed social protection.

Chapter 4 by Agnieszka Piasna critically spells out the pitfalls of measuring the size and scope of the platform economy. Surprisingly, despite its digital character and recording of the employment relationship in this type of economy, not much is known about its prevalence. Digital labour platforms are mostly not obliged to be transparent about their workforce, while platform workers are a hard-to-reach population as platform work is largely 'invisible' (see also Gruszka and Böhm 2020; Mateescu and Ticona 2021) or underreported by the workers themselves for tax or other reasons. Dedicated surveys by private or official statistical agencies are still in their infancy and thus of an explorative nature. They usually suffer from methodological difficulties like fuzzy taxonomy and measurement bias, inadequate data cleaning or self-selecting samples. Depending on the sample method used, estimates of the frequency and intensity of platform work diverge substantially between surveys, calling for caution in interpreting their results. Also, longitudinal data are commonly missing so that possible employment dynamics and trends are largely obscured and difficult to examine. Multi-apping - platform workers combining different platform tasks - adds further to the complication. 
Three major remarks can nevertheless be made based on survey results on the size of the platform economy. First, the platform economy is still marginal in quantitative terms if offset against the total working population - yet its importance lies in the implications for employment relations, labour markets and business models in certain industries in the conventional economy and the financing of social security systems. In other words, the platform economy warrants specific study as it is relatively distinctive from other transformations within capitalist development given its specific features like algorithmic management and its use of a contractor relationship to lessen labour costs and maximize labour control (Silver 2003; Vandaele 2021). That being said, as turnover among platform workers tends to be high, exposure to platform work might be quite sizable in absolute terms, with a considerable number of workers experiencing it at least for a short period.

Second, it is necessary to distinguish between different levels of economic dependency or attachment to the platform economy which can be measured by the extent the income level retrieved from platform work is able to "pay basic expenses' (Schor et al. 2020, p. 833). A first but simple bifurcation can be made between those workers for whom platform work is only supplemental to other (offline) earnings and the (smaller) group of workers who are platform dependent with platform work being their predominant source of income. The economic dependency of the latter group opens up possibilities for labour platforms to discipline their workers. A more fine-grained classification of economic dependence on platform remuneration can be achieved via introducing thresholds based on income retrieved from the conventional economy. Put differently, platform workers are not a homogeneous group - neither from the perspective of their attachment to the platform economy and the degree of algorithmic control nor from other perspectives like the specific occupation or industry they are working in or their level of education. Nevertheless, research from Europe has found that platform workers tend, on average, to be younger, although older workers are also involved (Piasna and Drahokoupil 2019; Urzì Brancati et al. 2020). Also, the proportion of workers with a migrant background is generally higher among platform workers than offline workers, and this is even more true where the income from platform work is at least 50 per cent (Urzì Brancati et al. 2020).

Third, while access in itself in the platform economy might be less marked by discrimination for certain worker categories than in traditional labour markets (van Doorn 2017), it is highly questionable if certain types of platform work, such as in transportation (including delivery), act as a stepping stone to jobs with better employment terms and conditions. Compared to workers not using digital labour platforms to find paid work, the employment trajectory of platform workers is marked by greater instability and fragmentation, with a higher incidence of non-standard contracts than workers solely employed 
offline (Piasna and Drahokoupil 2019; see also Borchert et al. 2018; van Doorn 2020).

The rise of organizational work practices associated with digital labour platforms should be appreciated within a longitudinal perspective of capitalist development. There are historical comparisons with similar types of piecework, informal and triangular work arrangements and decentralized and on-demand production systems in proto-industrialization areas of the Global North in the nineteenth century (Finkin 2016; Stanford 2017). Although such organizational arrangements still exist in certain non-digital occupations and industries today, their prevalence diminished with the advancement of the standard employment relationship in the twentieth century. While this kind of employment relationship remains dominant in the Global North, contingent forms of employment have nevertheless synchronously developed alongside it from the 1970s onwards (Crouch 2019; Herod and Lambert 2016; Hyman 2018).

In Chapter 5, Gérard Valenduc contributes to our understanding of the long-term trends that have given rise to platform work by analysing how developments in information and communications technologies and policies fostering labour market deregulation and liberalization have enabled and stimulated flexible work arrangements from the mid-1980s onwards. Call centres have been a quintessential example of the application of such arrangements that pertain to flexible working time and work location, atypical employment contracts or blurred subordination links.

Showing continuity with the past, the advancement of the platform economy after the crisis of the finance-led accumulation regime in 2007-2008 fits within this broader trend of contingent employment relationships and fissured workplaces (Weil 2014). Thus, while informality and precariousness have never been away in the Global South, the platform economy denotes a return to a (dystopian) past for workers in the Global North (van der Linden and Breman 2019). At the same time, making use of various innovations in digital technologies, digital labour platforms have a disruptive impact on existing markets and embody a (new) business model with two-sided markets (see Chapter 2). Valenduc also optimistically suggests, however, that the current digital transition can incorporate new types of work, like 'co-creation' (see also Seppänen et al. 2020) and 'open work', which can potentially lead to a withdrawal from the confining straitjacket of work arrangements associated with platforms.

Pierre Bérastégui and Sacha Garben explore further the theme of contingent employment in Chapter 6: they focus on the potential risks of platform-mediated work for the occupational health and safety of workers. The authors discern how the business model of digital labour platforms fits into, and is a profound deepening of, three ongoing and long-term trends in employment relations that are engrained in various industries in the conventional economy. 
First, the authors put algorithmic management and digital surveillance - rooted in managerial approaches towards engineering processes and not necessarily confined to the platform economy - central to understanding the monitoring, controlling and disciplining of workers. While the degree of algorithmic management and digital surveillance differs from platform to platform, in almost all instances their neutrality as merely technology-innovating companies is illusory. Second, the on-demand character of platform-mediated work implies that income volatility and feelings of job insecurity are omnipresent so that health and safety risks are augmented. Third, increased workplace fragmentation and the isolation of platform workers adds to the tendencies of mutual competition and undermines the building of professional identities.

These three trends associated with the business model of platforms have no uniform impact but are contingent on the type of platform work. Taking this platform variety into account, Bérastégui and Garben end on a positive note by hinting at the possibilities for labour agency and voice in certain platform types for applying and strengthening occupational health and safety regulations.

The diversity of the platform economy and labour agency is further analytically explored from a labour geography perspective in Chapter 7, written by Benjamin Herr, Philip Schörpf and Jörg Flecker. Applying the concepts of place and space reveal that the geographical appearance of digital labour platforms is, in fact, a trompe l'oeil. Thus, while online platforms seem 'placeless', the work is actually performed and territorially embedded somewhere, revealing regional patterns linked, for instance, to colonialization, cultural affinities and linguistic resemblances. Equally, whereas location-based platforms are not only subjected to local regulation, they are also a part of spatial structures, in particular where platform companies are operating at international level. Effective labour agency in the platform economy therefore entails the development of trade union strategies at interlinked, multiple geographical entities or spatial scales, which is a condition not at all different to the conventional economy. In this context, it is revealing that the headquarters of platform companies are geographically concentrated in a small number of countries (ILO 2021).

Herr and his colleagues use a local, national and transnational lens to examine labour agency in the platform economy. Two major conclusions can be drawn from this. First, it is clear that the opportunities for and obstacles to labour agency are unevenly spread across the types of platform, which is linked to their 'spatial fix'; that is, their geographical mobility of production for facilitating profitability and controlling labour (Johnson 2020; Silver 2003; Vandaele 2018, 2021). Workers particularly in location-based platform work, and specifically in food delivery, are commonly able to meet physically as the platforms themselves divide cities into certain areas where restaurants are clustered, which acts as a starting zone for the couriers. Couriers' under- 
standing of and experience with those shared log-in zones not only give rise to individual practices of resistance, but they also provide a spatial context fostering face-to-face contact and the building of collective identities and solidarities (Heiland 2021). Second, as a consequence, although union strategies are ideally multi-scalar from the outset, the emphasis on a specific scale in labour agency differs along with platform type. Thus, whereas labour agency in online platform work operates, almost by default, on a transnational scale, this is less evident in location-based platform work which is more strongly embedded in local and national regulatory contexts. Still, both main types of platform work experience the absence of a physical, shared workplace.

A bottom-up response to workers' isolation and spatial fragmentation is the emergence and development of digital, online communities of platform workers. Whether such communities are simply confined to the virtual world or can be considered prototypes of 'platform unions' remains to be seen. Their development, whether solely virtual or not, entails opening the lens to other collective organizations in the labour movement, like (platform) cooperatives, than simply (and rather myopically) analysing (long-established) trade unions (Atzeni 2020; Vandaele 2021). Even so, as the state has noticeably refrained from legal action so far, the combination of bottom-up approaches with regulatory creativity promises to be fruitful in the building of countervailing power vis-à-vis the platforms.

\subsection{REGULATING PLATFORM WORK: CHAPTERS 8 TO 11}

The four chapters in Part II of this volume engage with debates on the regulation of digital labour platforms. There are various regulatory ways of addressing the working conditions of platform workers and enforcing their fundamental rights, contingent on the type and features of platform work (see also Frenken et al. 2020; Koutsimpogiorgos et al. 2020).

In Chapter 8, Valerio De Stefano and Mathias Wouters propound the embedding of platforms in contemporary regulatory frameworks. Here, uncertainty about the employment status of platform workers is the key issue to be addressed. The authors review court cases across the globe to illustrate their arguments and point to inconsistencies in the classification of platform workers both between countries as well as within them. They consider two regulatory possibilities. First, some platforms can simply be treated as employers. This implies a proposal for a reversal of the usual burden of proof, such that platforms take on the responsibility for producing evidence that they do not act like an employer. Second, other platforms show similarities with private employment agencies, leading the authors to lean on two conventions of the ILO - the Private Employment Agencies Convention 1997 (No. 181) and the 
Home Work Convention 1996 (No. 177) - in making this interpretation of labour market intermediation and in proposing an international governance system for online platforms.

Chapter 9 by Sacha Garben addresses the regulatory options in the European context, addressing in particular legal developments at the level of the European Union (EU). Compared to organizational work arrangements which are based on non-standard types of employment in the informal or shadow economy, the author points out that the intentional use of such arrangements by platforms makes them more detectable and formal such that they may be made subject to regulatory frameworks.

In reality, applying and enforcing existing employment regulation to the triangular, or other, arrangements of platforms is challenging. Case-by-case determinations indeed show mixed results across EU member states, so the outcome is unpredictable. A reliance on existing regulations may not imply a static and passive response, however. The court may adapt the existing definitions of employment to the specific features of platform work. An alternative option is to narrow the group of people that will be considered self-employed. This can be done by introducing an intermediate category beyond the employed/self-employed dichotomy to extend some of the protection that applies to employees. However, this may prove an equally unsatisfactory solution as it still leaves room for interpretation. It may thus be preferable to narrow the self-employment category by introducing a presumption of employee status to platform workers. The approach of the European Trade Union Confederation (ETUC) follows this option, advocating the presumption of an employee relationship along with other measures to reduce the incentive to hire workers as self-employed. ${ }^{1}$ Finally, Garben also considers the option of providing specific protection for platform workers regardless of employment status through dedicated regulation.

Turning ultimately to the European level, following the developments in the relevant judgments of the EU Court of Justice shows a pattern that is not quite crystal clear. While the Court considered the intermediation service provided by Uber to be a transportation service, and thus that it was not a merely technology-innovating company, the judgment did not address the employment status of platform workers. Even so, the judgment could be a basis for further regulation in this regard. At the same time, the Court's older FNV judgment did in fact introduce legal uncertainty about the collective bargaining rights of platform and other self-employed workers. Interpretations of this judgment differ on whether platform workers who are considered self-employed are able to conclude collective agreements to set minimum employment terms and conditions or whether this might, alternatively, be at odds with European competition law. At the time of writing, the European Commission launched a first-stage consultation with the social partners - representatives of employ- 
ers and trade union organizations - on how to protect people working on platforms. It remains to be seen how, what and to what extent such a regulatory initiative will effectively reconcile the status of self-employment, within and beyond the platform economy, with collective bargaining rights.

The promise of self-regulation by platforms and their advocates can be considered one of the reasons why the state has been absent from regulating the platform economy. This narrative, rooted in a neoliberal ideology, is a falsehood, however, as Sai Englert, Mark Graham, Sandra Fredman, Darcy du Toit, Adam Badger, Richard Heeks and Jean Paul Van Belle show in Chapter 10. The authors discern two steps in how platforms are deliberately moulding regulations so that they fit with their dominant business model based upon algorithmic management and 'independent contractors'. First, the parlance of self-regulation by platforms is often a cover for a strategy based on simply rule-ignoring or rule-evading or interpreting existing regulations in an unconventional way to their advantage. States are, then, seemingly confronted with a fait accompli. Second, platforms try to perpetuate this deregulation or re-regulation or to install new regulatory frameworks. They do this via their lobbying power (see, for example, Corporate Europe Observatory and AK Europe 2019) or via their campaigning power in shaping public opinion to their regulatory preferences (see also Chapter 19).

Still, as several case studies in Part III of this volume demonstrate, the embeddedness of platforms in local and national regulatory contexts means that they intersect with existing regulations so that their actual operation is marked by contextual variation. Crucial in understanding this variation is also the resistance of platform workers, trade unions or their supporters via, for instance, industrial action and litigation. Other initiatives like that of the Fairwork Foundation of the Oxford Internet Institute, encouraging platforms to improve their employment terms and conditions by mapping their compliance with international minimum labour standards, have a role to play here, too. ${ }^{2}$

Given the deficiencies in self-regulation and the lack or insufficiency so far of an adequate state response, it is no wonder that trade unions have stepped in to guarantee minimum employment terms and conditions and social protection for platform workers and to assure their right to collective bargaining. Pursuing a logic-of-influence approach, mainstream unions in particular have initiated several cases of litigation over the past few years, related chiefly to the misclassification of workers in location-based platform companies as 'independent contractors' and to enforce the application to them of the existing regulations. However, the jury is still out on the success of such litigation by mainstream and, occasionally also, grassroots unions. Certainly, and the extent of union resources is an issue here, it can take some time before national court rulings are issued and, while they are setting legal precedents, they sometimes concern only individuals or small groups of platform workers. 
That litigation is an avenue with uneven outcomes also partly informs Chapter 11, by Simon Joyce and Mark Stuart. Mainly focusing on location-based platforms in the Global North, the authors supplement, in addition, the issue of the so far ambivalent results of the collective agreements which have been negotiated by mainstream unions. Indeed, while such agreements aim to incorporate platform workers, this is hardly the case in practice since most platform companies do not consider themselves as employers and thus do not adhere to collective agreements.

Pointing to the importance of the institutional context, some recent agreements regarding platform-based food delivery couriers in Nordic Europe do seem to be an exception, but they relate to couriers in a genuine employment relationship. Even in the case of Hilfr, a Danish platform company providing cleaning services in households, and which has been willing to negotiate with the union in question, the collective agreement of 2018 was thrown into doubt two years later by the Danish Competition and Consumer Authority which, following the European Court in the FNV case, considered some aspects of it to be at odds with competition law.

The Hilfr agreement also introduced a kind of third employment status, offering better employment terms and conditions than 'independent contractor' status would allow but poorer than in genuine employment. This has been criticized as mainstream unions being too pragmatic and lenient in the face of platform reality but, on the other hand, talk is cheap and it might be a first step in the direction that unions ideally strive for. Much of all of this can be seen as 'institutional experimentation' or regulatory frameworks 'in the making' from a historical and optimistic perspective (Degryse 2020).

The starting point and mainstay of collective bargaining strategies by mainstream unions remains the genuine employment relationship. As long as the status of 'independent contractor' is not adequately tackled by enforcing existing or new regulations, the effectiveness of the current strategies of mainstream unions is somewhat limited. Bottom-up self-organization among platform workers and grassroots unions is, almost by default, leading them to opt for a logic-of-membership approach; that is, a strategy of (app-based and online) mobilizing, organizing and direct action and in which formal union membership seems a secondary consideration (see also Vandaele et al. 2019). Designed to catch attention from the press and media, labelled as 'discursive power', old tactics are thereby combined with creative tactics bred by and adapted to the platform economy and therefore considered 'new'. So far, however, concessions by the platform companies seem limited whereas there is a danger as well of a certain 'mobilization fatigue' in adverse algorithmic-heavy circumstances.

Three additional points can be made here. First, platform companies are still a relatively new phenomenon, but mainstream unions have somewhat 
caught up after initially being puzzled about their rapid dynamics. There is, however, still room for learning from self-organization and grassroots unions. Second, the distinction between logic-of-influence and logic-of-membership approaches, linked respectively to mainstream unions and to self-organized and grassroots unions, is sometimes more complex in reality. Also, while historical, ideological or other tensions between grassroots and mainstream unions impedes any rapprochement, this might be less the case for self-organized platform workers, especially where grassroots unions are absent (see also Vandaele 2021). Finally, apart from some initiatives by, for instance, $I G$ Metall, the largest trade union in Germany, little is known so far about union action in the online platform economy, although here it is imaginable that a logic-of-influence approach by mainstream unions might be a better fit.

\subsection{CASE STUDIES ON ONLINE PLATFORM WORK: CHAPTERS 12 TO 14}

The remainder of the book explores the issues in greater detail through case studies of platform work. Part III includes case studies of online labour platforms while location-based platforms are covered in Part IV. The case studies are based on a range of research designs and methods for collecting and analysing data. Focusing on the actors, strategies and struggles involved in individual types of platform work, the research designs are, among others, informed by concepts of job quality and work-related capabilities and insights drawn from (historical) institutionalism, mobilization theory and the power research approach. Methods include ethnographic fieldwork such as informal conversations and participant observation; face-to-face (semi-structured) interviews with platform workers themselves or selected key persons like union officials, representatives of platforms, non-governmental officials and policy-makers; exploring platform transaction data; conducting survey-based research; and using descriptive and inferential statistics. Quantitative and qualitative methods are sometimes combined in a multi-method approach.

Many of the case studies included here share a(n) (implicit) comparative dimension, either by comparing the platform economy with similar developments or industries within the conventional economy via hypothetico-deductive reasoning or by making a comparison between well-defined geographical areas via an inductive approach. In geographical terms, the focus ranges from cities to regions within countries and to countries and country groups. Thus, the following cities and regions are covered in Part IV of this book: Beijing; Berlin; Cologne; Los Angeles; New York City; Oslo; Paris; Toronto; Vienna; and the state of Queensland in Australia - all demonstrating the highly city-based character of location-based platform work, in particular in transportation. Furthermore, platform workers in India, in particular its south-east region 
Tamil Nadu, as well as in Kenya, Malaysia, Mexico, Nigeria, the Philippines, Russia, South Africa, Ukraine, the United States (US) and Vietnam are studied.

Part III includes three chapters covering online platform work in low- to middle-income countries, covering both routine-like microtasks and specific skills-required macrotasks, and all three engage with the extent to which digital labour platforms stimulate economic and human development. Platform work is indeed often promoted and supported by policy-makers in lower-income countries via investment in digital architecture and training programmes.

Chapter 12 by Mark Graham, Vili Lehdonvirta, Alex J. Wood, Helena Barnard, Isis Hjorth and David Peter Simon analyses the conditions of online platform workers in the Global South. Here, such workers benefit from better remuneration than could be earned on local labour markets while they also appreciate the autonomy and flexibility of platform work. Yet, importantly, the benefits come at a cost. The authors report on the risks of platform workers in sub-Saharan Africa (Kenya, Nigeria and South Africa) and south-east Asia (Philippines, Malaysia and Vietnam). For instance, there are notable differences in remuneration between the aforementioned regions and platform workers performing micro- and macrotasks. Remuneration is also not equally distributed among platform workers, which can be explained by differences in reputations, while there is also a downwards pressure on platform-based remuneration due to overt oversupply. Job insecurity, due to a lack of employment protection, opacity (as clients are often unknown), discrimination and social isolation and a poor work-life balance (due to overwork and work intensification) are other features of platform work which negatively influence job quality. By way of at least mitigating these drawbacks, and for generating tax revenues, the authors propose to embed platforms in local labour market and welfare institutions.

In Chapter 13, with a strong focus on the gender dimension, Janine Berg, Uma Rani and Nora Gobel come to similar conclusions based on their survey findings of microtasks performed by platform workers in India. The three main incentives to engage in this type of platform work is to work from home, thus avoiding commuting, especially among women (which, therefore, reinforces gender segmentation on the labour market); to supplement income from other jobs; or to do it as a form of leisure. The authors focus in particular on remuneration and training opportunities and put this in comparison with India's industries involved in business process outsourcing: online platform work can be considered a type of offshore outsourcing, but to individuals instead of companies. The profile of the workers demonstrates indeed some similarities: both platform workers and workers in industries linked to business process outsourcing are young, well educated and they often have an information technology background. Also, work scheduling is comparable as both are performed during the evening or at night. Finally, the tendency to monitor, control 
and supervise platform work is, to a certain extent, similar to call centre work, although in the latter industry there is still room for human interaction instead of the anonymous algorithmic management associated with platform work.

As with Chapter 12, the remuneration from platform work in India is highly unevenly distributed and this deteriorates when unpaid work is taken into account. Indeed, on average, perhaps astonishingly, more than one-fifth of platform work is unpaid work involving activities such as searching for tasks or taking unpaid qualification tests. Including also unpaid work, the remuneration of microwork is lower on average when compared to similar work in the conventional economy although proportionately fewer women are employed in online platform work. In other words, skill arbitrage for platform-based microwork is quite unlikely as such workers are usually not in a position to set a higher price for their labour via the platforms than with local employers. Unlike in call centres, increases in remuneration due to tenure over time are non-existent on platforms. This can be explained by the constant influx of new labour on platforms and by the preferences of clients in the Global North to select fewer workers from the Global South for the more demanding tasks which are associated with higher remuneration. Furthermore, while work in call centres improves employability through skill upgrading, the (de-skilling) nature of platform-based microtasks does not allow much room for skill development and learning which can be used in other jobs outside the platform economy. The authors thus question governmental efforts to promote online platform work in India and the Global South in general.

Chapter 14 by Mariya Aleksynska, Andrey Shevchuk and Denis Strebkov is an antidote to the narrative of borderless, global labour markets through online platform work, at least when it concerns macrotasks. The authors review how a sole focus on English-language online platforms can be misleading: it underestimates the global size of the platform economy and it provides a false picture of the real geographical presence of digital labour platforms. There is a variety in the geographical scale of platforms. Online platforms might be part of global value chains but can also (additionally) operate in domestic and regional online labour markets. Reasons for the latter are manifold. First, a common language and culture eases communication and fosters trust between workers and clients, while geographic proximity means people are working in the same time zone. Second, depending on their degree of transferability and recognition, workers' skills can be valued differently in different markets which can give rise to domestic and regional online labour markets.

The authors illustrate the 'stickiness' of such markets by reference to domestic and regional online digital labour platforms in Russia and Ukraine, in which the Russian language delineates the regional dimension of the platforms (which are located in both countries). This multi-scalarity of the platforms should be taken into consideration. First, survey results show not only that 
some socio-demographic and other characteristics of platform workers differ along with the market, but also that remuneration and working hours are likely to be lower and less irregular, respectively, in domestic markets than in regional or international ones. Second, it also represents a case for the domestic and regional regulation of online platform work in addition to international regulation - not least because much of this type of work remains informal in Russia and Ukraine.

\subsection{CASE STUDIES ON LOCATION-BASED PLATFORM WORK: CHAPTERS 15 TO 20}

Almost all the chapters in Part IV cover location-based platform work in public settings, in particular within transportation. Food delivery and ride-sharing are the two industries that dominate the public discourse and have also attracted considerable attention from researchers. Chapter 15 by Andrea Santiago Páramo and Carlos Piñeyro Nelson, however, focuses on location-based platform work in a private setting: domestic cleaning. At the intersection between informality, precariousness and platform work, location-based platform work in private settings is under-researched (Ticona and Mateescu 2018; Mateescu and Ticona 2021).

Santiago Páramo and Piñeyro Nelson contrast a for-profit platform in Mexico and, as an ethical alternative, a non-profit platform in the US. Similarities in the workforce are manifold in both countries: it is a job overwhelmingly done by women, more than a quarter of whom are of indigenous origin in Mexico while most of those in the US have immigrant status, although undocumented. They are in informal employment arrangements, often facing discrimination, while they work in isolation and their job is considered of low status.

The analysis makes clear how the managerial prerogative which is built into algorithmic management does little to improve employment terms and conditions in the case of the for-profit platform in Mexico. In fact, the platform tends to reproduce cultural prejudices and stereotypes about cleaning and reinforces the existing dimensions of precarious work such as job insecurity, despite its choice of narrative centred around professionalizing domestic cleaning.

In contrast, the National Domestic Workers Alliance, an organization stimulating capacity-building among domestic workers and which campaigns for better rights for them, has established a non-profit platform for domestic cleaning in the US offering workers basic social protection. This 'community logic' (Frenken et al. 2020) demonstrates a future, countervailing avenue for organized labour, combining platform cooperativism with unionism or other types of workers' collective organization and representation (see also Scholz 2016; Schneider 2018), which is also reminiscent of the creative past of the labour movement. Based on a model of democratic ownership and govern- 
ance, platform cooperatives could set improved minimum employment terms and conditions, embrace data transparency and incorporate environmental concerns as well. Before such an alternative can be successful and competitive vis-à-vis the (international) platform corporations, however, this necessitates a number of requirements such as sufficient financial investment (for instance via crowdfunding), regulatory enabling frameworks at local or higher policy levels and adequate scalability and price-setting.

The remaining five chapters put the focus on an often much more 'visible' type of platform work - transportation - with three chapters on food delivery and two on ride-sharing. The geographical lens in all the chapters is directed towards cities and urban contexts. These contexts, as then highlighted by Maria Figueroa in Chapter 21 - the concluding chapter - seem to offer a fertile ground for 'institutional experimentation' by the social actors.

Turning first to platform-based food delivery, and probably also other industries within the platform economy (see, for example, Bucher et al. 2020), worker resistance - where it exists at all - often has an individualized character (Barratt et al. 2020; Heiland 2021; Shanahan and Smith 2021). Individualized coping strategies have been explained by food delivery couriers' mainly 'entrepreneurial' interpretations of their employment terms and conditions, being manipulated by algorithmic management and their own internalization of the platforms' neoliberal discourse so that the organizational work arrangements associated with the platforms are sustained and reinforced rather than altered. While this has given rise to pessimistic accounts of labour agency in the (food delivery) platforms, the three case studies here offer a more optimistic view of the possibilities of collective resistance and counter-discourses among platform-based food delivery couriers, as well as of their self-organization and unionization.

Chapter 16 by Kristin Jesnes, Denis Neumann, Vera Trappmann and Pauline de Becdelièvre studies the mobilization process of platform-based food delivery couriers in Cologne in Germany, Oslo in Norway and Paris in France, as well as the variety in the couriers' collective (proto-)organization, coalition-building with trade unions and the effectiveness of social protest. The authors accentuate the similarities in the mobilization process of the couriers between the three cities, irrespective of the specific contractual arrangement, while simultaneously allowing for subjective understandings of trade unionism among those couriers who took a leadership role and the contextual differences in the prevailing national system of industrial relations.

As documented elsewhere for other cities as well (for example, Vandaele 2020), some couriers have taken up a leadership role, driving the mobilization process. Thus, a critical mass of couriers has been instrumental in identifying how algorithmic management, combined with non-standard contractual arrangements, negatively affects employment terms and conditions, especially 
regarding remuneration. They have made fellow couriers aware of this 'algorithmic injustice', attributing it to human management within the food delivery platforms. They have also fostered group identification in online digital communities and offline physical gatherings at meeting points and defended social protest, sometimes including industrial action, as an effective means of mitigating or undoing the feelings of 'algorithmic injustice'. The forging of coalitions with trade unions and the selection of specific unions have been (partially) dependent on the subjectivities and norms of those key couriers, however. In turn, those city-dependent configurations of courier unions - the extent to which couriers are formally working together with unions - have oriented the action repertoire and the aims and effectiveness of social protest. As a result, the outcomes of protests have varied, much in line with the dominant logic of the national industrial relations system.

The study on organizing food delivery bike couriers in Toronto, Canada, by Raoul Gebert in Chapter 17, with an equal focus on labour agency, runs fairly parallel with Chapter 16. Yet, the author shifts the lens from the couriers to the trade unions in this case study, with the couriers' grassroots association being seen as a pre-existing structure from the viewpoint of the union (Vandaele 2020, p. 13).

While platform-based food delivery can be considered a fairly novel industry, challenging prevailing regulatory and institutional arrangements for unionization and collective bargaining, unions have of course previously been confronted with new industries or new groups of workers within existing industries. Union responses towards new groups of (precarious) workers have been diverse (Heery 2009; Keune and Pedaci 2020) and the advent of digital labour platforms is no different. Gebert understands the union response from the Canadian Union of Postal Workers as 'institutional experimentation'. First, the union legally endeavoured to establish 'dependent contractor' status for the couriers, instead of the traditional 'salaried employee' status, which resulted in precedent being set in Canadian labour jurisprudence in February 2020. In this way, platform-based food delivery could act as leverage for regulating other industries within the platform economy. Second, under the influence of its construction of a relationship with the union, 'Foodsters United', initially a grassroots association of bike couriers who shared a strong collective identity, shows features of the 'whole-worker approach' (McAlevey 2016) and community unionism today; that is, a presence going beyond a sole focus on collective bargaining. Although the organizing drive of the union was successful, Foodora, the platform company in this case, left the Canadian market in spring 2020, demonstrating the evident geographical binarity behind location-based platforms: they are either present and operating in a given locality or they are not (Vandaele 2021). 
Chapter 18 by Jack Linchuan Qiu, Ping Sun and Julie Chen engages with the food delivery platforms themselves in Beijing, and especially how algorithmic management is manipulating employment terms and conditions. A short (labour) market analysis deciphers that platform-based food delivery is ultra-competitive and a very significant market in China in terms of revenue and employment. Similar to food delivery in other countries (in the Global North), low remuneration and a high level of turnover mark the labour market. Interestingly, the industry in China has been characterized by a de-flexibilization, with incentive structures and algorithmic management encouraging full-time engagement with very little working time flexibility. Couriers are young, they have a migratory background (coming from rural areas in the Chinese context) and employment relationships are complex, due also to the involvement of temporary staffing agencies, and are often initially informal. Couriers perform emotional labour when dealing with customers, influencing their ratings and thus remuneration, while the platforms try to discipline them via gamification and managing their working time in order to maximize orders and minimize delivery time.

As in the conventional economy, however, labour control through algorithmic management is not absolute: courier resistance is, individually and collectively, via the avenues of deceiving and subverting the algorithms, social protest and industrial action. The value of platform-based food delivery has, in particular, been highlighted during the Covid-19 pandemic within urban lockdown areas and local authorities have put pressure on platforms to smooth the edges of algorithmic management so that couriers' employment terms and conditions are improved.

The authors conclude by considering platform-based food delivery a 'digital utility' - that is, a public service delivered by platforms but driven by public values embedded in solid regulatory frameworks - since it has increased its relevance in everyday life in Chinese cities, becoming an essential part of the urban service infrastructure.

Chapter 19 by Hannah Johnston and Susanne Pernicka turns to ride-sharing - another very visible industry within the location-based platform economy. Their account reflects the historical, pendular tendency of regulation, deregulation and re-regulation within the taxi sector in urban contexts. The authors add a constructive, subjective dimension into their analysis as they put the perceived legitimacy of power resources, or symbolic power, central to an understanding of the variation in resistance and regulatory outcomes vis-à-vis ride-sharing in the cities of Berlin, Los Angeles, New York City and Vienna. To explain the responses of platform workers and unions towards ride-sharing platforms, they develop a power resources perspective that takes into account the interplay of local, national and transnational scales. 
Given their strong institutional power and symbolic recognition of this power resource, trade unions in Vienna oriented themselves to a successful logic-of-influence approach so that it looks like ride-sharing platforms such as Uber will be embedded into regulatory frameworks and institutions, at least at national level. Workers' institutional power has diminished over time in Berlin, while their associational power is underdeveloped so that regulation tends to favour the new ride-sharing platform companies.

Institutional power and the legitimacy thereof are comparatively weaker in the US, although with considerable differences between states and, thus, the two cities studied here, Los Angeles and New York City. While a logic-of-membership approach is pursued in both cities, (platform) workers in Los Angeles have, so far, not been able to build sufficient associational power. Their efforts are largely oriented to the city level while platform companies have been able to deregulate the taxi sector at state level in California, especially as the symbolic struggle is currently also bending towards them. Thus, political authorities and the public in general are inclined towards an interpretation of platform companies in the taxi sector as a technological app-based solution to transportation needs. This is in contrast to New York City, where (platform) workers in ride-sharing have been engaging in a symbolic struggle about the meaning of platform work and where they have been able to build associational power which has been instrumental in the building of institutional power at local regulatory level.

Interestingly, an initiative has been recently taken by three labour activists and progressives to launch a driver-owned ride-sharing app-based platform, The Drivers Cooperative, as an alternative to platform companies (Nolan 2020). Its crowdfunding campaign for developing this initiative quickly reached its goal which hints at how information asymmetry and a lack of trust between funders and investors can be transcended by platform cooperativism and how this stimulates interaction between the future driver-owners and potential users (Talonen et al. 2020).

Finally, in Chapter 20, David Peetz analyses regulatory responses towards the health and safety risk - injuries or fatalities due to accidents - associated with ride-sharing in the state of Queensland, Australia. While it looks like there have been far more motor vehicle fatalities since the arrival of Uber, it is clear that vehicle passenger transport is an industry which presents above-average risk. Platform workers in ride-sharing in Australia are, however, not covered by injury compensation insurance as they have so far been considered as 'independent contractors'.

In 2018, the Queensland government reviewed the injury compensation system and the extent to which this could be extended to workers in location-based platforms like ride-sharing. The review made the innovative proposal to redefine insurance coverage so that workers under agency arrange- 
ments would be included and to require the payment of injury compensation premiums by intermediaries or agencies, in this case by digital labour platforms in the taxi sector. The premiums, which would also have an experience-rated character, would be set as a proportion of the commission received by the platform from the customer. Feedback to the review's recommendations varied, with the ride-sharing platform companies themselves either rejecting the proposals or being lukewarm about them.

After the publication of the review, the Covid-19 pandemic broke out, impeding further steps as the policy focus shifted towards handling the pandemic. Needless to say, the pandemic has increased the health risks for platform workers in ride-sharing while their income from this kind of work has both dropped and become even more insecure. ${ }^{3}$

\subsection{PROSPECTS}

Writing amidst the Covid-19 pandemic, it is still rather uncertain whether the economic consequences of the pandemic will stimulate the growth of the platform economy. While the complexity of labour platforms can be characterized by their Janus and Proteus tendencies, Proteus's prophetic ability is not of much help here with evidence about the impact of the pandemic on platform workers being scant and patchy. As far as it concerns location-based platforms, the economic effect is, in all probability, uneven, with some industries (like platform-based food and grocery delivery) booming, while others (such as ride-sharing) suffer declining demand. Online platforms saw a drop in demand across the board in the second quarter of 2020 but that was followed by a recovery with demand for information technology-related services growing rapidly (cf. Stephany et al. 2020). Also, certain platforms might benefit from shifting consumer preferences, new business strategies and an acceleration in remote work or from states' post-Covid-19 policy responses regarding platform work.

Despite the self-regulating efforts of certain platforms to offer some health insurance schemes or support funds, there is no doubt that most platform workers, especially where it concerns their main income, are essentially bearing the risks during the pandemic (Fairwork 2020; ILO 2021). At the same time this exposure might push the need for a regulatory framework cushioning such risks rather higher up the policy agenda.

Furthermore, as employment via digital labour platforms or the conventional economy looks like compensating vessels (Schor et al. 2020), at least in the Global North, taking into account developments within conventional labour markets provides some guidance for the future of labour platforms. Increased unemployment due to restructuring as a consequence of the pandemic will undoubtedly feed a fresh reservoir of on-demand labour. All of 
this will demand a post-pandemic regulatory embeddedness of digital labour platforms at different policy levels.

As to what that regulatory embeddedness might look like, Chapter 21 by Maria Figueroa helpfully prompts us towards the potential contents of a policy framework within which a response might be made to the challenges laid down by the activity of location-based and online platforms.

The fluidity of the context in which platforms operate, even ignoring the effects of Covid-19, indicates that institutional experimentation is, as Figueroa also identifies, likely to be a key part of that policy framework for some time to come as the social actors, and regulatory agencies, get to grips with the meaning and implications of the business model developed by the platforms. This is fertile ground for experimentation - but, at the same time, it is also uncertain ground in the sense that there are question marks over the sustainability of that model given the sizable year-on-year financial losses being recorded by some of the platforms and which, as the court rulings mount up, are heading in one direction only as the competitive effects of their regulatory advantage are eaten away.

The bulk of the call for institutional experimentation might seem to fall on labour organizations - and, as many of the contributions to this volume point out, there is actually quite a bit going on there already, both among mainstream trade unions and grassroot organizations. More could, inevitably, always be done and there remain some crucial barriers at the organizational level and institutional level, as a result not least of the understanding gap, but none of these contributions call into question the continuing logic of collective action. Above that principle, however, the debate is a broad and lively one.

\section{NOTES}

1. See ETUC Resolution on the protection of the rights of non-standard workers and workers in platform companies (including the self-employed), adopted 28 October 2020, available at www.etuc.org/en/document/etuc-resolution-protection-rights -non-standard-workers-and-workers-platform-companies.

2. On the Fairwork Foundation, see https://fair.work/en/fw/homepage/.

3. Meanwhile, in that other type of location-based platform work, namely food delivery, Deliveroo couriers have elected seven health and safety representatives from their Sydney ranks after five fatalities occurred between September and October 2020 (Australian Financial Review, 4 January 2021). The representatives are paid by Deliveroo for the time spent dealing with safety issues.

\section{REFERENCES}

Adams-Prassl, A. and J. Berg (2017), When home affects pay: an analysis of the gender pay gap among crowdworkers, 6 October, accessed 15 February 2021 at https:// papers.ssrn.com/abstract $=3048711$. 
Aloisi, A. (2020), 'Hierarchies without firms? Vertical disintegration, outsourcing and the nature of the platform', Quaderni 8th Giorgio Rota Best Paper Award, 11-32.

Atzeni, M. (2020), 'Worker organisation in precarious times: abandoning trade union fetishism, rediscovering class', Global Labour Journal, 11 (3), 311-314.

Barratt T., C. Goods and A. Veen (2020), “'I'm my own boss ...": active intermediation and "entrepreneurial" worker agency in the Australian gig-economy', Environment and Planning A: Economy and Space, 52 (8), 1643-1661.

Berg, J. (2016), 'Income security in the on-demand economy: findings and policy lessons from a survey of crowdworkers', Conditions of Work and Employment Series 74, Geneva: ILO.

Berg, P., E. Appelbaum, T. Bailey and A. L. Kalleberg (2004), 'Contesting time: international comparisons of employee control of working time', ILR Review, 57 (3), 331-349.

Berger, T., C. B. Frey, G. Levin and S. R. Danda (2019), 'Uber happy? Work and well-being in the "gig economy", Economic Policy, 34 (99), 429-477.

Borchert, K., M. Hirth, M. Kummer, U. Laltenberger, O. Slivko and S. Viete (2018), 'Unemployment and online labor', ZEW Discussion Paper 18-023, Mannheim: ZEW.

Bosch, G. (2004), 'Towards a new standard employment relationship in western Europe', British Journal of Industrial Relations, 42 (4), 617-636.

Bucher, E. L., P. Kalum Schou and M. Waldkirch (2020), 'Pacifying the algorithm: anticipatory compliance in the face of algorithmic management in the gig economy', Organization, 28 (1), 44-67.

Cant, C. (2018), 'The warehouse without walls: a workers' inquiry at Deliveroo', Ephemera, 20 (4), 131-161.

Charles, J., I. Ferreras and A. Lamine (2020), 'A freelancers' cooperative as a case of democratic institutional experimentation for better work: a case study of SMart-Belgium', Transfer, 26 (2), 157-174.

Corporate Europe Observatory and AK Europe (2019), 'Über-influential? How the gig economy's lobbyists undermine social and workers rights', Brussels: Corporate Europe Observatory and AK Europa.

Crouch, C. (2019), Will the gig economy prevail?, Cambridge: Polity Press.

Degryse, C. (2020), 'Du flexible au liquide: le travail dans l'économie de plateforme', Relations Industrielles/Industrial Relations, 74 (4), 660-683.

Drahokoupil, J. (ed.) (2015), The outsourcing challenge: organizing workers across fragmented production networks, Brussels: ETUI.

Drahokoupil, J. and A. Piasna (2019), 'Work in the platform economy: Deliveroo riders in Belgium and the SMart arrangement', Working Paper 2019.01, Brussels: ETUI.

Dubal, V. B. (2017), 'The drive to precarity: a political history of work, regulation, and labor advocacy in San Francisco's taxi and Uber economies', Berkeley Journal of Employment and Labor Law, 38 (1), 73-135.

Dubal, V. B. (2020), 'An Uber ambivalence: employee status, worker perspectives, and regulation in the gig economy', in D. Das Acevedo (ed.), Beyond the algorithm: qualitative insights for gig work regulation, Cambridge: Cambridge University Press, pp. 33-56.

Fairwork (2020), The gig economy and Covid-19: looking ahead. September 2020, Oxford: The Fairwork Project.

Finkin, M. (2016), 'Beclouded work, beclouded workers in historical perspective', Comparative Labor Law and Policy Journal, 37 (3), 603-618. 
Florisson, R. and I. Mandl (2018), Platform work: types and implications for work and employment - literature review, Dublin: Eurofound.

Frenken, K., T. Vaskelainen, L. Fünfschilling and L. Piscicelli (2020), 'An institutional logics perspective on the gig economy', in I. Maurer, J. Mair and A. Oberg (eds), Theorizing the sharing economy: variety and trajectories of new forms of organizing, Bingley: Emerald Publishing, pp. 83-105.

Gegenhuber, T., M. Ellmer and E. Schüßler (2020), 'Microphones, not megaphones: functional crowdworker voice regimes on digital work platforms', Human Relations, accessed 15 February 2021 at https://doi.org/10.1177/0018726720915761.

Gerber, C. (2020), 'Community building on crowdwork platforms: autonomy and control of online workers?', Competition and Change, accessed 15 February 2021 at https://doi.org/10.1177/1024529420914472.

Gerber, C. and M. Krzywdzinski (2019), 'Brave new digital work? New forms of performance control in crowdwork', in S. Vallas and A. Kovalainen (eds), Work and labor in the digital age, Bingley: Emerald Publishing, pp. 121-143.

Grabher, G. and J. Köning (2020), 'Disruption, embedded: a Polanyian framing of the platform economy', Sociologica, 14 (1), 95-118.

Grabher, G. and E. van Tuijl (2020), 'Uber-production: from global networks to digital platforms', Environment and Planning A: Economy and Space, 52 (5), 1005-1016.

Gray, M. L. and S. Suri (2019), Ghost work: how to stop Silicon Valley from building a new global underclass, Boston, MA: Houghton Mifflin Harcourt.

Gruszka, K. and M. Böhm (2020), 'Out of sight, out of mind? (In)visibility of/in platform-mediated work', New Media and Society, accessed 15 February 2021 at https://doi.org/10.1177/1461444820977209.

Hall, J. V. and A. B. Krueger (2018), 'An analysis of the labor market for Uber's driver-partners in the United States', ILR Review, 71 (3), 705-732.

Heery, E. (2009), 'Trade unions and contingent labour: scale and method', Cambridge Journal of Regions, Economy and Society, 2 (3), 429-442.

Heiland, H. (2021), 'Controlling space, controlling labour? Contested space in food delivery gig work', New Technology, Work and Employment, accessed 15 February 2021 at https://doi.org/10.1111/ntwe.12183.

Herod, A. and R. Lambert (2016), 'Neoliberalism, precarious work and remaking the geography of global capitalism', in R. Lambert and A. Herod (eds), Neoliberal capitalism and precarious work: ethnographies of accommodation and resistance, Cheltenham, UK and Northampton, MA, USA: Edward Elgar Publishing, pp. 1-35.

Hyman, L. (2018), Temp: how American work, American business, and the American dream became temporary, New York: Viking Penguin.

ILO (2021), World employment and social outlook: the role of digital labour platforms in transforming the world of work, Geneva: International Labour Office.

Jesnes, K. and S. M. Nordli Oppegaard (eds) (2020), Platform work in the Nordic models: issues, cases and responses, Copenhagen: Nordic Council of Ministers.

Johnson, H. (2020), 'Labour geographies of the platform economy: understanding collective organizing strategies in the context of digitally mediated work', International Labour Review, 159 (1), 25-45.

Keune, M. and M. Pedaci (2020), 'Trade union strategies against precarious work: common trends and sectoral divergence in the EU', European Journal of Industrial Relations, 26 (2), 139-155.

Koutsimpogiorgos, N., J. van Slageren, A. M. Herrmann and K. Frenken (2020), 'Conceptualizing the gig economy and its regulatory problems', Policy and Internet, $12(4), 525-545$. 
Kuhn, K. M. and A. Maleki (2017), 'Micro-entrepreneurs, dependent contractors, and instaserfs: understanding online labor platform workforces', Academy of Management Perspectives, 31 (3), 183-200.

Lehdonvirta, V. (2018), 'Flexibility in the gig economy: managing time on three online piecework platforms', New Technology, Work and Employment, 33 (1), 13-29.

Mateescu A. and J. Ticona (2021), 'Invisible work, visible workers: visibility regimes in online platforms for domestic work', in D. Das Acevedo (ed.), Beyond the algorithm: qualitative insights for gig work regulation, Cambridge: Cambridge University Press, pp. 57-81.

McAlevey, J. (2016), No shortcuts: organizing for power in the new gilded age, Oxford: Oxford University Press.

Nolan, H. (2020), 'New York City drivers cooperative aims to smash Uber's exploitative model', In These Times blog, 10 December, accessed 16 February 2021 at https://inthesetimes.com/article/new-york-city-drivers-cooperative-uber-lyft.

Panteli, N., A. Rapti and D. Scholarios (2020), "If he just knew who we were": microworkers' emerging bonds of attachment in a fragmented employment relationship', Work, Employment and Society, 34 (3), 476-494.

Peck, J. and R. Phillips (2020), 'The platform conjuncture', Sociologica, 14 (3), 73-99.

Pesole, A., M. C. Urzì Brancati, E. Fernández-Macías, F. Biagi and I. González Vázquez (2018), Platform workers in Europe evidence from the COLLEEM survey, Luxembourg: Publications Office of the European Union.

Piasna, A. and J. Drahokoupil (2019), 'Digital labour in central and eastern Europe: evidence from the ETUI Internet and Platform work survey', Working Paper 2019.12, Brussels: ETUI.

Piasna, A. and J. Drahokoupil (2021), 'Flexibility Unbound: Understanding the Heterogeneity of Preferences among Food Delivery Platform Workers', Socio-Economic Review, https://doi.org/10.1093/ser/mwab029.

Schneider, N. (2018), Everything for everyone: the radical tradition that is shaping the next economy, New York: Nation Books.

Scholz, T. (2016), Platform cooperativism: challenging the corporate sharing economy, New York: Rosa Luxemburg Stiftung.

Schor, J. B., W. Attwood-Charles, M. Cansoy, I. Ladegaard and R. Wengronowitz (2020), 'Dependence and precarity in the platform economy', Theory and Society, 49 (5-6), 833-861.

Seppänen, L., C. Spinuzzi, S. Poutanen and T. Alasoini (2020), 'Co-creation in macrotask knowledge work on online labor platforms', Nordic Journal of Working Life Studies, accessed 15 February 2021 at https://doi.org/10.18291/njwls.123166.

Shanahan, G. and M. Smith (2021), 'Fair's fair: psychological contracts and power in platform work', International Journal of Human Resource Management, accessed 15 February 2021 at https://doi.org/10.1080/09585192.2020.1867615.

Silberman, M. 'Six' and H. Johnston (2020), Using GDPR to improve legal clarity and working conditions on digital labour platforms, Working Paper 2020.05, Brussels: ETUI.

Silver, B. (2003), Forces of labor: workers' movements and globalization since 1870, Cambridge: Cambridge University Press.

Stanford, J. (2017), 'The resurgence of gig work: historical and theoretical perspectives', Economic and Labour Relations Review, 28 (3), 382-401.

Stephany, F., M. Dunn, S. Sawyer and V. Lehdonvirta (2020), Distancing bonus or downscaling loss? The changing livelihood of US online workers in times of 
Covid-19, preprint, SocArXiv, 20 April, accessed at https://doi.org/10.31235/osf.io/ vmg34.

Talonen, A., J. Pasanen and O.-P. Ruuskanen (2020), 'Exploring the co-operative form's potential in crowdfunding: a non-monetary perspective', FIIB Business Review, accessed 15 February 2021 at doi.org/10.1177/2319714520920798.

Ticona, J. and A. Mateescu (2018), 'Trusted strangers: carework platforms' cultural entrepreneurship in the on-demand economy', New Media and Society, 20 (11), 4384-4404.

Urzì Brancati, M. C., A. Pesole and E. Fernández-Macías (2020), New evidence on platform workers in Europe: results from the second COLLEEM survey, Luxembourg: Publications Office of the European Union.

van der Linden, M. and J. Breman (2019), 'Informalizing the economy: the return of the social question on a world scale', in M. van der Linden (ed.), The global history of work: critical readings, Vol. III: Labour market, London: Bloomsbury Publishing, pp. 254-271.

van Doorn, N. (2017), 'Platform labor: on the gendered and racialized exploitation of low-income service work in the "on-demand" economy', Information, Communication and Society, 20 (6), 898-914.

van Doorn, N. (2020), 'Stepping stone or dead end? The ambiguities of platform mediated domestic work under conditions of austerity. Comparative landscapes of austerity and the gig economy: New York and Berlin', in D. Baines and I. Cunningham (eds), Working in the context of austerity: challenges and struggles, Bristol: Bristol University Press, pp. 49-69.

Vandaele, K. (2018), 'Will trade unions survive in the platform economy? Emerging patterns of platform workers' collective representation and voice', Working Paper 2018.05, Brussels: ETUI.

Vandaele, K. (2020), 'From street protest to improvisational unionism: platform-based food delivery couriers in Belgium and the Netherlands', Trade Unions in Transformation 4.0, Berlin: Friedrich-Ebert-Stiftung.

Vandaele, K. (2021), 'Collective resistance and organizational creativity amongst Europe's platform workers: a new power in the labour movement?', in J. Haidar and M. Keune (eds), Work and labour relations in global platform capitalism, Cheltenham, UK and Northampton, MA, USA: Edward Elgar Publishing and Geneva: ILO.

Vandaele, K., A. Piasna and J. Drahokoupil (2019), “"Algorithm breakers” are not a different "species": attitudes towards trade unions of Deliveroo riders in Belgium', Working Paper 2019.06, Brussels, ETUI.

Weil, D. (2014), The fissured workplace: why work became so bad for so many and what can be done to improve it, Cambridge, MA: Harvard University Press.

Wood, A. and V. Lehdonvirta (2019), 'Platform labour and structured antagonism: understanding the origins of protest in the gig economy', accessed 16 February 2021 at https://ssrn.com/abstract=3357804.

Wood, A., V. Lehdonvirta and M. Graham (2018), 'Workers of the internet unite? Online freelancer organisation among remote gig economy workers in six Asian and African countries', New Technology, Work and Employment, 33 (2), 95-112.

Wood, A., M. Graham, V. Lehdonvirta and I. Hjorth (2019), 'Networked but commodified: the (dis)embeddedness of digital labour in the gig economy', Sociology, $\mathbf{5 3}$ (5), 931-950. 
Xhauflair, V., B. Huybrechts and F. Pichault (2018), 'How can new players establish themselves in highly institutionalized labour markets? A Belgian case study in the area of project-based work', British Journal of Industrial Relations, 56 (2), 370-394. 